\title{
The Potential of TerraSAR-X to Observe Wind Wave Interaction at the Ice Edge
}

\author{
Claus Gebhardt, Jean-Raymond Bidlot, Sven Jacobsen, Susanne Lehner, Member, IEEE, P. Ola G. Persson, \\ and Andrey L. Pleskachevsky
}

\begin{abstract}
This paper performs a study on sea state and wind fields at the ice edge boundary by utilizing information from different sources including synthetic aperture radar (SAR) satellite imagery, weather and sea state analyses from the European Centre for Medium-Range Weather Forecasts, shipborne in-situ measurements, and AMSR2 ice charts. The basis is a Stripmap scene from the TerraSAR-X satellite acquired on October 18, 2015, at $\sim 18$ UTC, in support of the cruise of the research vessel R/V Sikuliaq in the Beaufort/Chukchi Sea. This scene covers an area with a length of more than $100 \mathrm{~km}$ and comprises both the marginal ice zone and, for the largest part, open water. The wave and wind field is retrieved from satellite at high spatial resolution using empirical retrieval algorithms. These algorithms are XWAVE and XMOD-2 specifically developed for X-Band SAR. XWAVE allows for determining the significant wave height not only for long swell waves, but also for short waves with their wave pattern being hardly visible from SAR. The latter is based on the analysis of image spectrum parameters and spectral noise. As well, the possibility of the imaging quality of longer waves visible from SAR being affected by SAR-specific nonlinear imaging effects is narrowed down. Both the wave and wind field are found to exhibit considerable spatial variability, and their relationship is analyzed. The relevance of the findings of this study with respect to wave/ice modeling is discussed.
\end{abstract}

Index Terms-Arctic marginal seas, marginal ice zone (MIZ), sea state, TerraSAR-X, wind.

\section{INTRODUCTION}

I $\mathrm{N}$ THE context of a changing sea ice and wave climate, the build-up of ocean waves in ice-free parts of the Arctic seas

Manuscript received September 15, 2016; revised December 21, 2016; accepted January 5, 2017. Date of publication April 11, 2017; date of current version July 17, 2017. The work at DLR was in part funded by the Office of Naval Research under the DRI "Sea State and Boundary Layer Physics of the Emerging Arctic Ocean" (grant N00014-13-1-0303). Funding for the analysis of the Sikuliaq data was provided by the U.S. Office of Naval Research to the University of Colorado under Grant N00014-16-1-2018. Sea ice concentration data for October 18, 2015 were made available via http://www.meereisportal.de (under Grant REKLIM-2013-04). (Corresponding author: Claus Gebhardt.)

C. Gebhardt, S. Jacobsen, S. Lehner, and A. L. Pleskachevsky are with the Maritime Safety and Security Lab, Remote Sensing Technology Institute (IMF), German Aerospace Center (DLR), 28199 Bremen, Germany (e-mail: Claus.Gebhardt@dlr.de; Sven.Jacobsen@dlr.de; Susanne.Lehner@dlr.de; Andrey.Pleskachevsky@dlr.de).

J.-R. Bidlot is with the Earth Modelling Section, European Centre for Medium-Range Weather Forecasts (ECMWF), Reading RG2 9AX, U.K. (email: jean.bidlot@ecmwf.int).

P. O. G. Persson is with the Cooperative Institute for Research in Environmental Sciences, University of Colorado, and the Physical Sciences Division, Earth System Research Laboratory, National Oceanic and Atmospheric Administration, Boulder, CO 80305 USA (e-mail: ola.persson@ colorado.edu).

Color versions of one or more of the figures in this paper are available online at http://ieeexplore.ieee.org.

Digital Object Identifier 10.1109/JSTARS.2017.2652124 and their impact on both the coastline and marginal ice zone (MIZ) gain growing attention. The reduction of Arctic sea ice over the last few decades has been yielding the first indications for increasing wind fetch and an increase in wave generation [26]. Related sea state trends are governed by different factors including the timing and amount of ice retreat in summertime and the frequency and strength of wind forcing. In general, those trends are based on satellite climatology and model runs. Current efforts are undertaken to improve the representation of ice in sea state models, among others by means of observations, e.g., [27].

In recent years, several strong swell wave events in Arctic waters have been recorded by in-situ measurements during ship campaigns [5]. Consistency checks with models were performed to interpret observations [2]. Moreover, case studies on swell wave events in the MIZ were conducted using synthetic aperture radar (SAR) imagery from satellites [1], [8], [21]. Article [8] is based on a Stripmap scene from the TerraSAR-X satellite (TS-X), which provides a snapshot of two different swell wave systems penetrating deeply into the MIZ off the coast of Eastern Greenland. Different sources of wavelength variability, both ice and nonice related, were identified, and the results were crosschecked with a model hindcast from the European Centre for Medium-Range Weather Forecasts (ECMWF).

In the following, a case study with a focus on sea state variability at the open-water side of the ice edge is performed. The basis is a TS-X scene in the Beaufort/Chukchi Sea acquired on October 18, 2015, in support of the cruise of the research vessel R/V Sikuliaq. For the cruise report, see [25]. Further information on the cruise support by TS-X satellite images can be found in [14]. Here, wind measurements from R/V Sikuliaq are utilized to provide understanding of the meteorological conditions and to rule out the possibility of some $180^{\circ}$ direction ambiguity remaining from wind analysis of SAR images.

It is noted that sea state variability in the vicinity of the ice edge is of importance with respect to the ocean-atmosphere-ice interaction. As indicated in the modeling study of [3], airflow in the marine atmospheric boundary layer is affected differently by different types of sea state. By implication, accounting for the sea state variability is crucial for the successful implementation of ocean-atmosphere interactions into wave and ice models.

This paper is organized as follows. In Section II, the TS-X scene that is the basis for subsequent analysis is introduced, and an overview on the methods of retrieving sea state and wind parameters from SAR satellite images is given. In Section 


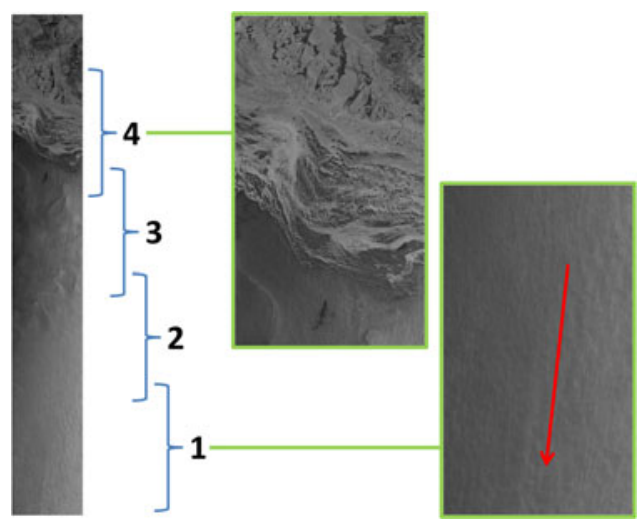

Fig. 1. Left to right: Stripmap scene from TerraSAR-X acquired on October 18, 2015, at ca. 18 UTC. For the geographical position of the scene, see Fig. 2. From bottom to top, the scene is divided into four images, numbered as $1-4$. On the right, images 4 and 1 are given enlarged. The upper part of image 4 shows ice-infested water. Below, this is followed by open water. The latter exhibits currents which appear as line patterns (not under analysis in the following). In the open-water portion of the scene, wind streaks are visible. In image 1 (enlarged on the right), a red arrow gives the approximate streak direction. By implication, wind direction from northeast is indicated (see also Fig. 9).

III, the meteo-marine situation on the day of data acquisition is described. Weather and sea state forecasts from ECMWF, in-situ measurements from R/V Sikuliaq, and an ice chart from AMSR2 are used. Section IV reproduces empirically gathered knowledge on wind wave growth under fetch-limited condition, which is relevant in this study. Section $V$ presents the results and a discussion. First, the sea state and wind data resulting from the TS-X scene are described comprehensively, and sources for identified sea state variability are discussed. Second, the role of SAR-specific nonlinear imaging effects is analyzed. Third, a consistency check with ECMWF data is performed. The findings of this study are summarized in Section VI.

\section{Sea State AND Wind Data From the TERRASAR-X SATELLITE}

The core of the TS-X instrumentation is a SAR, which operates at X-band, i.e., at a wavelength of $3.1 \mathrm{~cm}$. As any SAR observation, TS-X is practically independent of sunlight and cloud conditions. For details, see http://www.dlr.de/TerraSAR-X. TS-X scenes are acquired in different imaging modes and polarizations. For the mode of single-polarized Stripmap imaging, the recommended performance range (RPR) was specified to comprise incidence angles from around 20-45 [7].

Here, a Stripmap scene from October 18, 2015, at ca. 18 UTC, is under analysis. It was acquired in VV polarization (VV means vertical-vertical), which is widely used for ocean applications. The incidence angle at satellite acquisition was around $26.5^{\circ}$. The scene is shown in Fig. 1. Its geographical position is highlighted by a black polygon inside an ice concentration map in Fig. 2.

Among a list of TS-X scenes accompanying the Sikuliaq cruise (catalogue accessible via EOWEB-Earth Observation Data Service-DLR), this scene was selected for case study as it provides a snapshot of considerable gradients of significant wave height $\left(H_{S}\right)$ and wind speed. This is a suitable condition

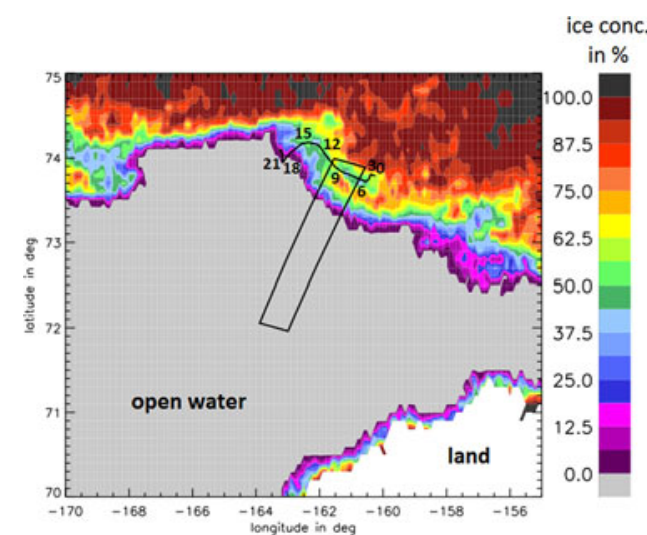

Fig. 2. For October 18, 2015, a local sea ice concentration map off the northwest coast of Alaska is shown. It is based on data from AMSR2 [22]. Color scale on the right. Gray/white color is open water/land, respectively. The area of the Stripmap scene from TerraSAR-X, presented in Fig. 1, is highlighted by a black polygon. The curved black line is the track of R/V Sikuliaq on this day, with the numbers showing the ship location at the given hour (UTC).

for analyzing the relationship between both. Moreover, the wind speed is not more than moderate. Otherwise, sea state patterns might be strongly overlaid by wind features in the SAR image, which usually appear as wind streaks. They are overlaid to the sea surface and typically originate from water/land (or water/ice) boundaries. In the Arctic, those wind patterns are believed to be enhanced by atmospheric instability arising from the advection of relatively cold Arctic air over open water.

TS-X Stripmap scenes have a width of $30 \mathrm{~km}$ in the crossflight direction of the satellite, and their in-flight length may extend up to several hundred kilometers. The spatial resolution of the Stripmap mode is around $3 \mathrm{~m}$. The Stripmap scene used in the following is of multilook ground range detected (MGD) type. MGD processing involves ground-range projection, i.e., conversion from slant-range to ground-range coordinates (as widely known, range is synonymous with the cross-flight direction of the satellite). As well, speckle noise is reduced by applying the multilooking technique. MGD is a default product type having a pixel spacing of $1.25 \times 1.25 \mathrm{~m}$. Stripmap scenes are subdivided into single images of typically $30 \times 50 \mathrm{~km}$.

With the TS-X satellite having a relatively low orbit of only $\sim 500 \mathrm{~km}$ altitude, SAR-specific nonlinear imaging effects of ocean waves are of relatively small importance. The azimuthal cutoff of waves, which is one of these effects, minimizes for waves traveling close to the range direction. TS-X is able to image ocean waves down to $\sim 30 \mathrm{~m}$ length without being subject to cutoff in imaging. This is based on empirical knowledge from large amounts of wavelengths detected by TS-X [18, appendix] .

In the following, sea state and wind field analysis is applied to Stripmap images from TS-X. For sea state analysis, image subscenes undergo 2-D fast Fourier transformation (FFT) resulting in a power spectrum each. The positions of the spectral maxima immediately yield wave parameters such as the peak wavelength and the direction. Comparisons of the peak wavelength and the direction from TS-X image spectra and collocated buoy measurements resulted in correlations higher than $90 \%$ [4]. 
The FFT resolution in the wave number space is given by $\frac{2 \pi}{L}$, with $L$ being the subscene length. Here, subscenes of $\sim 5 \times 5 \mathrm{~km}$ are used. For the subsequent retrieval of $H_{s}$, the version of the XWAVE algorithm described in [19] is employed. This algorithm version was optimized for use in coastal waters. Accordingly, it is able to account for short and random water waves, which appear in image spectra as noise due to SAR-specific nonlinear imaging effects. Note that the algorithm determines the total value of $H_{S}$ and does not distinguish between co-occurrent systems of wind and swell waves. The wind retrieval is based on the XMOD-2 algorithm [15]. For inferring the wind speed, a priori knowledge of the wind direction is required. Wind patterns in SAR images, i.e., the aforementioned wind streaks, typically provide a priori estimates of the wind direction [12]. Both the $H_{S}$ and the wind algorithm are based on nonlinear geophysical model functions. These are empirical relationships including wave/wind parameters, spectral parameters, parameters of the satellite image acquisition geometry, and coefficients. The identification of parameters and the tuning of coefficients are based on comparisons of large datasets against collocated datasets from in-situ measurements or models. The algorithms perform well for incidence angles in the RPR and beyond, as follows, e.g., from [13]. Note that these retrievals are designed for use in ice-free open water. In the following, they are used to analyze the open-water side of the ice edge, which itself is ice-free. For this, the Stripmap scene in Fig. 1 is subdivided into four single images, each of them $30 \times 50 \mathrm{~km}$ in area. $H_{S}$ and wind retrieval are applied to images $1-3$, not to image 4 , which shows ice-infested water for large parts. Image 4 has a certain overlap with image 3 so that its ice-free part is still included in the latter.

\section{MEteo-Marine SituAtion}

\section{A. Large-Scale Situation}

Note that Alaska and North Western Canada were under anomalous high-pressure influence in October 2015 because of a persistent Rossby wave pattern [16]. This fact is in line with the high-pressure influence described below.

The cruise of R/V Sikuliaq was supported by wave and weather forecasts from different sources. In Fig. 3, a 6-h forecast of the sea-level pressure and $10-\mathrm{m}$ wind speeds and directions is shown along with a concurrent 30 -h forecast of significant wave height and mean wave period and direction, both valid at 18 UTC on October 18, 2015. They were provided by the ECMWF. Note that these were operational forecasts without true wave ice interaction but the very crude treating of all sea ice areas with ice concentration above $30 \%$ as land (i.e., no waves). The geographical location of the TS-X Stripmap scene is shown in each panel. During this day, atmospheric low pressure was centered over west-central Alaska, with two high-pressure centers in the upper left and upper right of the chart and moving from west to east, primarily over the newly formed sea ice. A sequence of charts (not shown here) indicates the eastward progression of the $1016-\mathrm{hPa}$ isobar at near $74^{\circ} \mathrm{N}$ during the course of this day. The gradient between these high- and low-pressure centers produces a moderate to strong easterly wind over the Beaufort
Sea and north to northeasterly wind over the Chukchi Sea. There are two maxima of wind speed: one over the Beaufort Sea and the other over the Chukchi Sea (represented by red color in the synoptic chart). There is a clear gradient of wind speed in the proximity of the ice edge, which is near the northern end of the Stripmap. In the lower chart, the maxima and gradients of $H_{S}$ obviously follow those of the wind speed.

Around the image acquisition area of TS-X, swell waves from the east with periods up to $8 \mathrm{~s}(\sim 100$-m wavelength) and wave heights up to $1.2-1.5 \mathrm{~m}$ are forecasted. Clear gradients of wind speed and $H_{S}$ are evident along the orientation of the Stripmap scene.

\section{B. From Regional Scale to Local Scale}

Fig. 2 provides a local sea ice concentration map for October 18, 2015. The concentration data are based on AMSR2 [22] available via http://www.meereisportal.de. For the figure, a latitude-longitude grid of $0.1^{\circ} \times 0.1^{\circ}$ was used, with each grid point assigned the nearest AMSR2 data on this day. In addition, the area of the TS-X scene introduced in Section II and the daily track of R/V Sikuliaq are highlighted. For the latter, ship positions are marked by the hour of the day. The map indicates an area of open water bounded by the Alaska coast to the southeast and the ice to the north. The Sikuliaq traversed the ice on the northern edge of the Stripmap between 6 and 9:30 UTC on this day, about 9-12 h before the Stripmap was acquired.

Wind speed and direction and air and surface temperature were measured by multiple sensors mounted on the R/V Sikuliaq and immersed in the nearby water. These have been edited and combined to provide a high-quality dataset [17] and are presented in Fig. 4 for October 18. Before 15:30 UTC, these measurements show that the wind was weak $\left(1-3 \mathrm{~m} \cdot \mathrm{s}^{-1}\right)$ and coming predominantly from the east-southeast $\left(110^{\circ}\right)$. Since the ship was traveling through ice being $5-30 \mathrm{~cm}$ thick, the surface temperature was below the sea-water freezing point at $\sim-3{ }^{\circ} \mathrm{C}$. The air temperature was colder than the surface by 2-3 ${ }^{\circ} \mathrm{C}$, indicating that the atmospheric surface layer was unstable, even over the ice. Since the ocean temperature near the ice edge was either at its freezing point or slightly warmer, as shown by the surface temperature measured when the ship went into open water between 17 and 21:30 UTC, any off-ice airflow would lead to significantly unstable conditions over the adjacent open water. At $\sim 15: 30$ UTC, the ship traversed a sharp transition zone $\sim 50 \mathrm{~km}$ west of the Stripmap location and $2.5 \mathrm{~h}$ before its acquisition. The wind turned to northerly direction and increased in strength to $9-10 \mathrm{~m} \cdot \mathrm{s}^{-1}$, the air temperature decreased, and the surface pressure increased (not shown). Hence, this transition zone has characteristics of a frontal feature. Further analysis suggests that this feature was associated with a band of enhanced boundary layer convection evident in optical satellite imagery (not shown) and was propagating eastward at $\sim 5 \mathrm{~m} \cdot \mathrm{s}^{-1}$ at the latitude of the ship. The enhanced convection suggests boundary-layer convergence of airflow, consistent with the change in wind direction observed by the ship. Furthermore, this small-scale front-like feature had the same eastward propagation speed as the western high-pressure system shown in Fig. 3 and appears to be associated with it. 


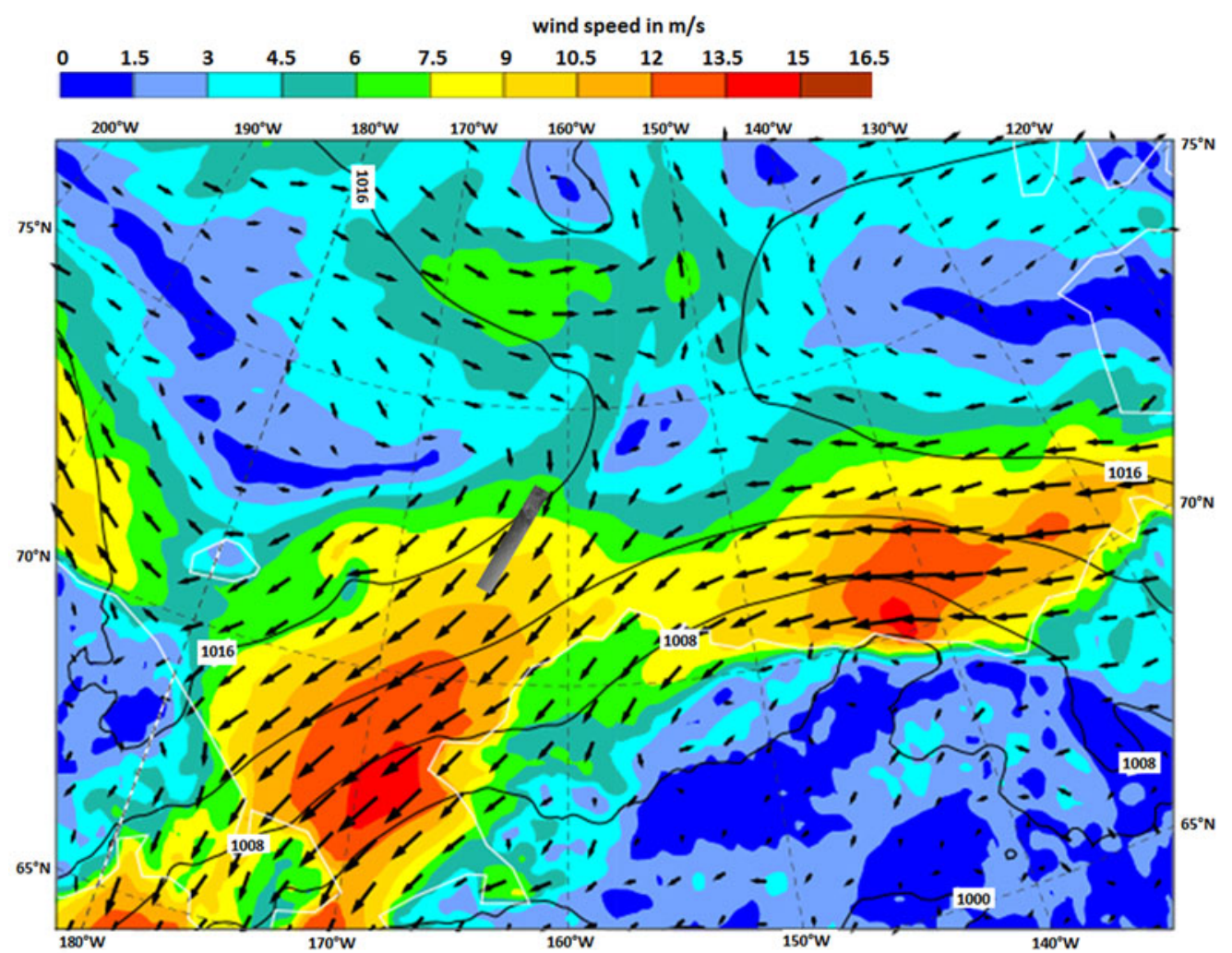

(a)

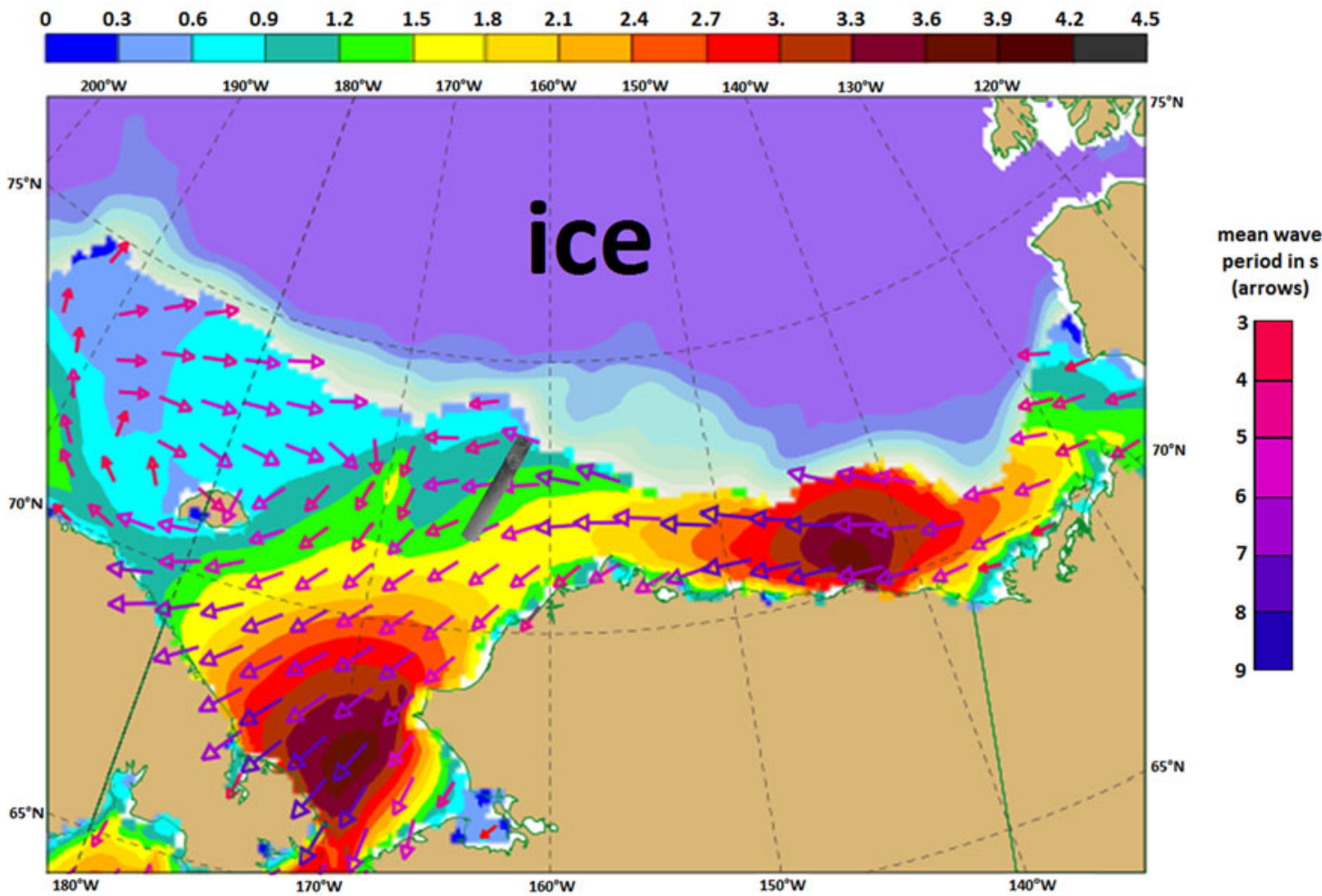

(b)

Fig. 3. ECMWF weather and wave forecast for October 18, 2015, at 18 UTC. (Top) Black arrows indicate the wind direction and speed (length). The wind speed is also given by colored contours (color scale on the top). (Bottom) In the middle and lower part of the plot, arrows show the mean wave direction and the mean wave period (color). The color scale of arrows is on the right. Moreover, $H_{S}$ is given by colored contours ( $H_{S}$ color scale on top of the plot). In the upper part of the plot, the contours are colored white to purple instead. Here, the colors indicate ice concentrations of $10 \%, 20 \%, \ldots, 100 \%$. According to the representation of ice in the forecast model described in Section III-A, ice concentrations larger than $30 \%$ are not overlaid by arrows, i.e., waves are nonexistent. 

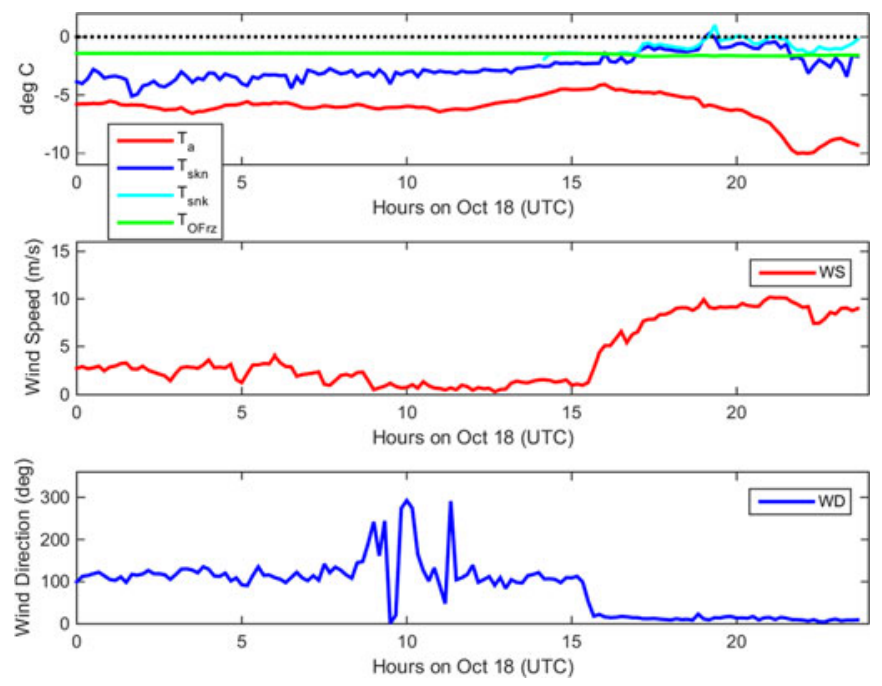

Fig. 4. On-board measurements from R/V Sikuliaq on October 18, 2015. (Top) Air temperature $T_{a}$, the surface temperature $T_{\mathrm{skn}}$ and $T_{\mathrm{snk}}$, and ocean freezing point $T_{\mathrm{OFrz}}$ are provided. Note that $T_{\mathrm{snk}}$ was measured by a thermistor system, which was deployed only close to open water. That is why it is only available in the late hours of the day. (Middle and bottom) Wind speed and direction (in degree from north) are given.

The eastward propagation speed of this front-like transition zone would have placed it over the ice at the northwestern corner of the Stripmap scene at the time of the TS-X overpass $(\sim 18$ UTC). Hence, the front had not yet reached the area of the TS-X Stripmap scene at the time of its acquisition. By implication, the open-water region of the scene is still subject to the weak winds measured by R/V Sikuliaq before 15:30 UTC. With the vessel having cruised close to the top-end of the Stripmap scene (within the ice part of the scene), an easterly wind direction is expected there accordingly. Wind streaks in the open-water part of the Stripmap indicate the wind direction having turned to northeasterly there (for details, see Fig. 9). The latter would also be consistent with the forecasted surface winds shown in Fig. 3. For the subsequent retrieval of wind speed from satellite, an $a$ priori value of $45^{\circ}$ is selected for the wind direction.

\section{EMPIRICAL FETCH RELATIONS ON WIND WAVES IN THE OCEAN}

The growth of wind sea is powered by interaction with local wind. The theory of wind waves builds upon the idealized situation of fetch-limited geometry. This implies a constant wind directed across a boundary line (e.g., coastline). Thus, the wind acts on waves over a clearly defined distance, the so-called fetch. The generation of waves starts from a completely calm sea at time $t=0$.

The basis for our knowledge on the fetch-limited generation of wind waves are field experiments. Among the early campaigns, the Joint North Sea Wave Project (JONSWAP) [10] is widely known. Its main experiment was conducted in 1969. It consisted of a wave array extending from the North Frisian Island of Sylt westward into the North Sea over a distance of 160 $\mathrm{km}$. Depending on the wind condition, this came close to an ideal fetch-limited geometry. Based on statistical methods, empiri- cal relationships between wind parameters and wave properties were derived. They are typically expressed using nondimensional quantities. For the wave energy $\epsilon$, wave frequency $\omega$, and fetch $x$, their nondimensional counterparts are given by

$$
\begin{aligned}
& \tilde{\epsilon}=\epsilon \frac{g^{2}}{U_{10}^{4}} \\
& \tilde{\omega}=\omega \frac{U_{10}}{g}
\end{aligned}
$$

and

$$
\tilde{x}=x \frac{g}{U_{10}^{2}}
$$

with $g$ being the gravitational acceleration and $U_{10}$ the wind speed $10 \mathrm{~m}$ above the sea surface.

However, certain inconsistency between one another showed up from different field experiments. This was corroborated by the Sea Wave Modeling Project (SWAMP) Group [23], an initiative comparing the results of sea state models. This gave rise to the combination and reanalysis of observational datasets. The study of [11] revisited the existing field data. Measurements under variable and decreasing/increasing wind were excluded from analysis. The remaining data were separated into the cases of stable and unstable atmospheric stratification. For stable/unstable stratification (and also for the composite data), fetch relations of the following form were obtained:

$$
\tilde{\epsilon}=\alpha \tilde{x}^{\beta}
$$

with $\alpha$ and $\beta$ being case-dependent constants. The values of $\beta$ are given by 0.76 and 0.94 for stable and unstable stratification, respectively ( 0.9 for composite data).

By implication, the wave energy increases as a function of fetch $x$ and wind speed $U_{10}$. At the ice edge, the fetch length, however, cannot readily be estimated. That is because the ice edge typically has a fuzzy shape. Moreover, the ice concentration changes intermittently between large values in the interior MIZ to zero at the open ocean boundary. Figs. 1 and 2 illustrate this. As observed during the Sikuliaq cruise, wave growth may already start in waters infested or surrounded by ice some kilometers before encountering the open-water boundary (see [25], for the cruise day of October 18). For overall fetch lengths of several tens of kilometers, which are given in the following, this is a considerable source of uncertainty. That is why, fetch values are assumed to be well defined, but not further specified from SAR images in the following. Apart from that, TS-X observation on wave growth with the fetch being sharply limited by a coastline was already reported in the article of [6].

With respect to SAR images, the following relationship between wave growth and wind speed is expected. For a uniform wind field, each image point has a characteristic fetch $x$. For simplicity, we approximate $\beta$ in (4) to be equal to 1 . Based on (1), (3), and (4), $x=$ const is equivalent with $\tilde{\epsilon} U_{10}^{2}=\frac{\epsilon}{U_{10}^{2}}=\mathrm{const}$ (const denotes a constant value). This, in turn, gives $\epsilon \sim U_{10}^{2}$ ( $\sim$ means proportionality). Inserting this into the following relation $H_{S}=4 \sqrt{\epsilon}$, see e.g. [20], yields $H_{S} \sim U_{10}$. Of course, real wind and wave fields have departures from the idealized situation assumed above. Wind varies in space and time. In 

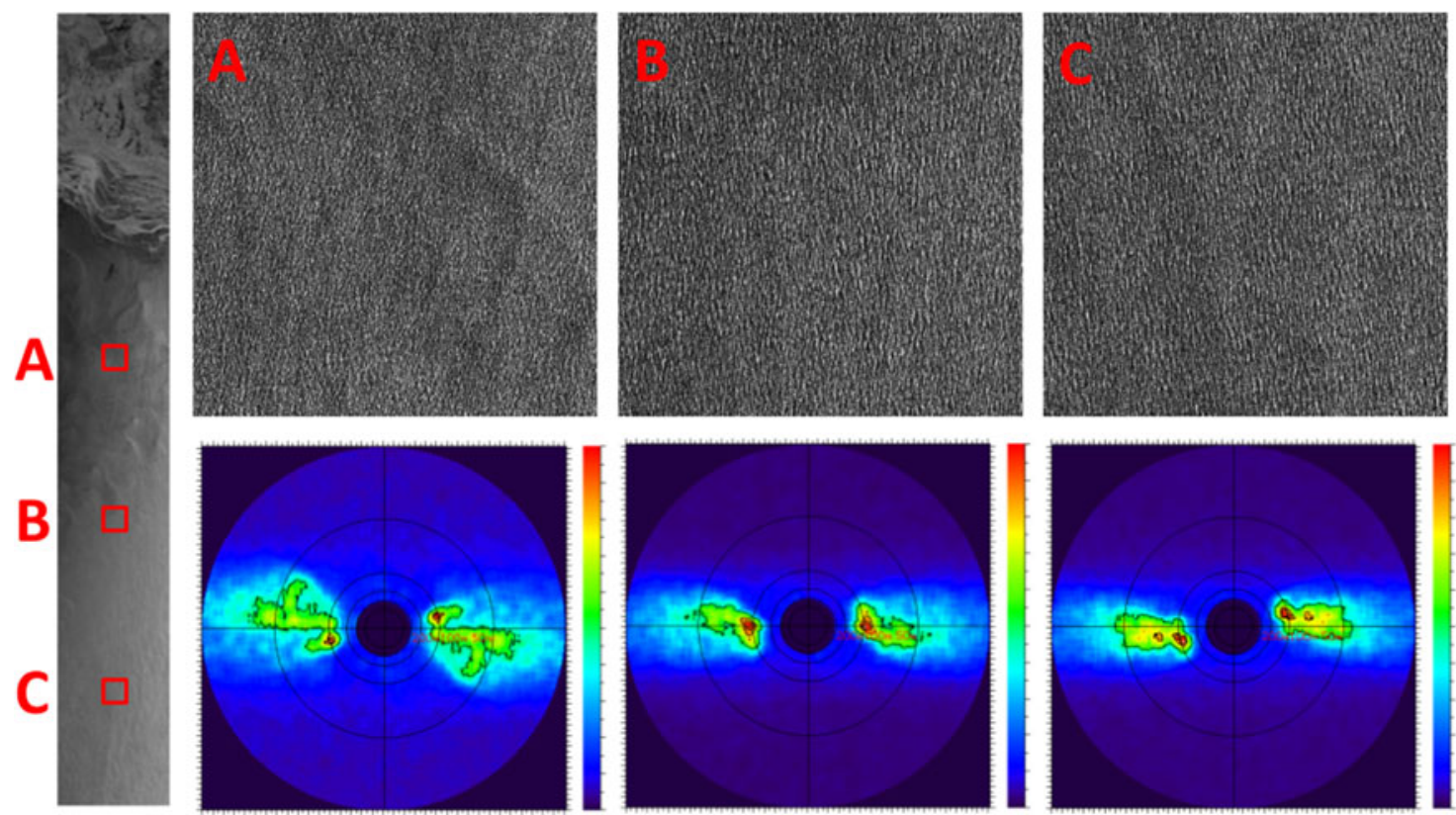

Fig. 5. (Left) Three subscenes are highlighted, labeled as A, B, and C. On the right, these subscenes are shown enlarged. For each of them, the corresponding image spectrum is provided below. In the spectra, the wavelengths of 50,100, and $150 \mathrm{~m}$ are represented by black circles. High-pass filtering was applied to wavelengths larger than $200 \mathrm{~m}$ in order to exclude spectral signals from potential longer wave-like structures, e.g., wind streaks. Hence, the spectral energy was forced to zero in the middle of the spectra. A pattern of swell waves with a wavelength of around $100 \mathrm{~m}$ is clearly visible from the subscenes. This swell wave system is represented by a pronounced peak in the spectra (colored red). Due to a $180^{\circ}$ ambiguity, this peak appears actually twice in each spectrum, on the left and right of its middle. Note that short wind waves are not evident from the subscenes and image spectra, likely being subject to SAR-specific nonlinear imaging effects, as explained in Section V-B.
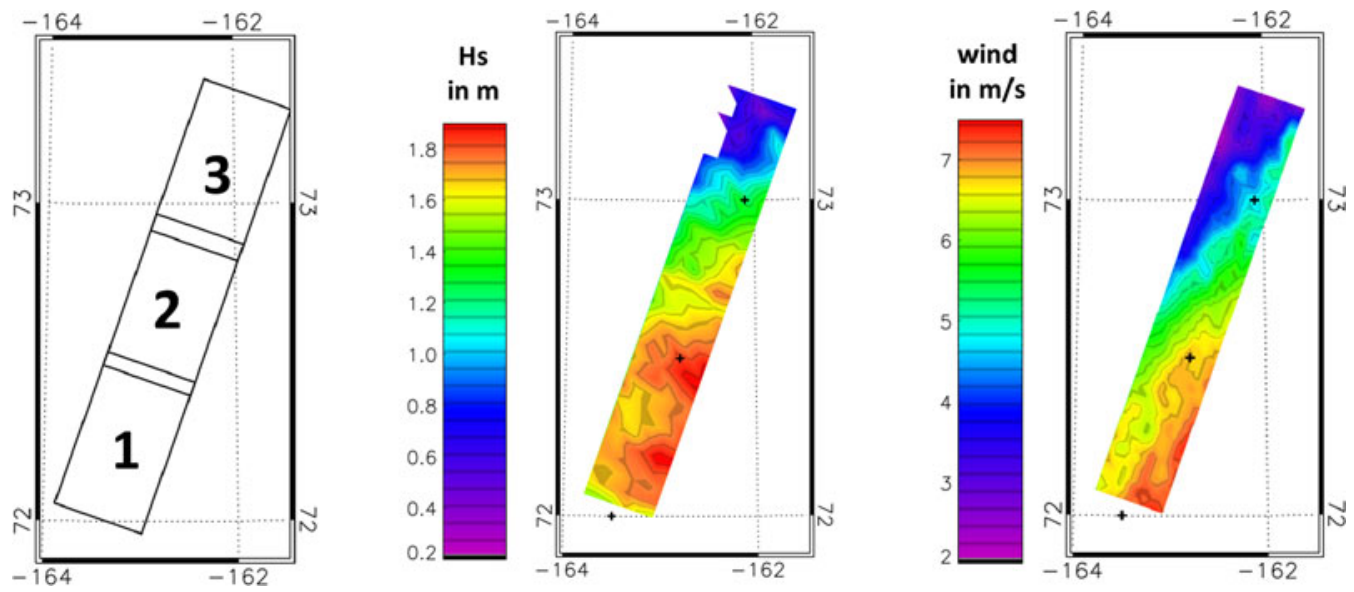

Fig. 6. (Left) Geographical positions of satellite images 1-3 are shown (for the definition of images, see Fig. 1). (Middle) $H_{S}$ data from all three images are plotted (values lower than $0.2 \mathrm{~m}$ were omitted). (Right) Same for $U_{10}$ data. Both in the $H_{S}$ and $U_{10}$ plot, the geolocations of the ECMWF wave spectra shown in Fig. 8 are marked by plus signs.

addition, the wave height generated by local wind may be overlaid by that from the passage of swell waves. However, considerable correlation between $H_{S}$ and $U_{10}$ may still be given, particularly if swell is not dominant. To date, the latter applies in general to the Beaufort/Chukchi Sea, e.g., [26]. Based on a wave record over summer/fall 2012, Thomson and Rogers[24] pointed out that correlation between wind speed and wave energy is still notable for fetch lengths on the order of $1000 \mathrm{~km}$.

Kahma and Calkoen[11] obtained as relation between peak wave frequency and fetch for unstable atmospheric stratification

$$
\tilde{\omega}_{p}=14.2 \tilde{x}^{-0.28} \text {. }
$$

In the following, the dispersion relation for ocean waves in deep water is used for the conversion of the peak wave frequency $\omega_{p}$ to peak wave wavelength $\lambda_{p}$ :

$$
\omega^{2}=(2 \pi f)^{2}=g k
$$

with $\omega=\frac{2 \pi}{T}$ being the angular frequency of waves, $T$ the wave period, $f$ the wave frequency, $k=\frac{2 \pi}{\lambda}$ the wave number, and $\lambda$ the wavelength. 


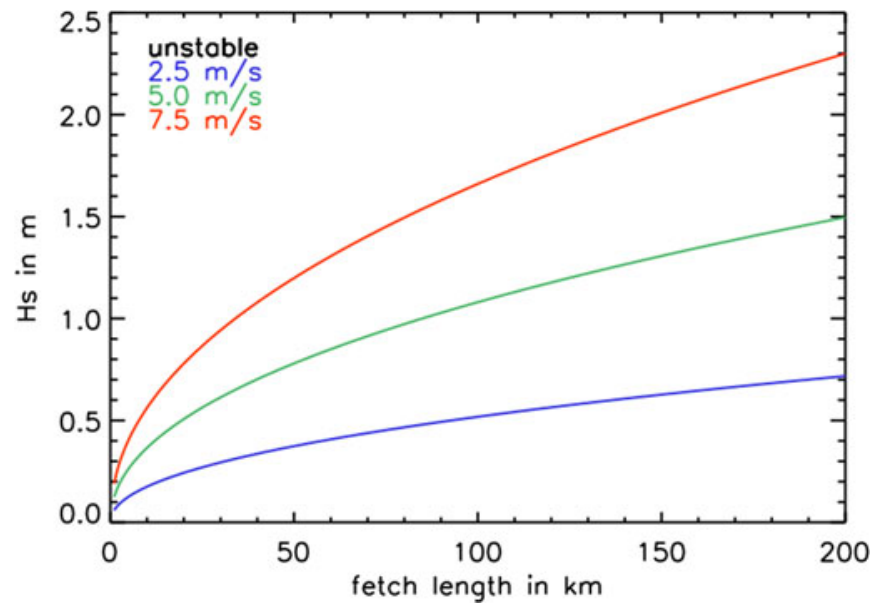

Fig. 7. Growth of $H_{S}$ as a function of the fetch for the wind speeds of $2.5 \mathrm{~m} \cdot \mathrm{s}^{-1}$ (blue), $5 \mathrm{~m} \cdot \mathrm{s}^{-1}$ (green), and $7.5 \mathrm{~m} \cdot \mathrm{s}^{-1}$ (red). This is based on the empirical fetch relations for the case of unstable atmospheric stratification.

\section{RESUlTS AND DisCUSSION}

\section{A. Observed Sea State Variability}

In the left part of Fig. 5, the Stripmap scene from TS-X introduced before is shown with three subscenes of $\sim 5 \times 5 \mathrm{~km}$ highlighted, labeled as A, B, and C. These subscenes represent different portions of the open-water part of the Stripmap. Subscene A was selected from the interior part of image 3, B from image 2, and $\mathrm{C}$ from image 1 . On the right, an enlargement of the subscenes and their FFT-based image spectra are presented. From all subscenes, a sea state pattern is clearly evident. The peak wavelength resulting from the image spectra is around $100 \mathrm{~m}$. The peak wave direction is close to the right-to-left image direction. Since the scene is tilted clockwise by around $19.5^{\circ}$ with respect to the north-to-south direction, the waves are coming from about $110^{\circ}$ and moving toward $290^{\circ}$. Note that this is the identical direction of the easterly wind measured by the R/V Sikuliaq near the northern end of the Stripmap earlier on this day. Moreover, this is consistent with a field of swell waves forecasted by the ECMWF as follows from Section IIIA. Note that the characteristics of the selected subscenes are not quite identical when quantifying the impact of nonlinear imaging effects, as pointed out in Section V-B.

In Fig. 6, contour plots showing satellite data of $H_{S}$ and $U_{10}$ from TS-X images 1-3 are provided. These data were inferred by sea state and wind analysis, as described in Section II. They were determined following a raster pattern with steps of $2500 \mathrm{~m}$ between adjacent points for each of the images. Each piece of data is centered within the corresponding image subscene of $\sim 5 \times 5 \mathrm{~km}$ which underwent FFT. Color scales comprising the $H_{S}$ range from 0.2 to $1.9 \mathrm{~m}$ and the $U_{10}$ range from 2 to $7.5 \mathrm{~m} \cdot \mathrm{s}^{-1}$, respectively, are given on the left of the plots. From image 3 to $1, H_{S}$ increases from values of $0.2-0.5 \mathrm{~m}$ to values of $1.5-2 \mathrm{~m}$ and $U_{10}$ from 2 to $6-7 \mathrm{~m} \cdot \mathrm{s}^{-1}$ and more. Note that $H_{S}$ values lower than $0.2 \mathrm{~m}$ were omitted in the $H_{S}$ plot of the figure (by contrast, all wind data are shown in the $U_{10}$ plot). As follows, below-threshold $H_{S}$ data were obtained in the upper part of satellite image 3 , which is near the ice edge.

\section{Normalised 2D-spectrum on Oct. 18, 2015, 18 UTC at $73^{\circ} \mathrm{N}, 162.1^{\circ} \mathrm{W}$}

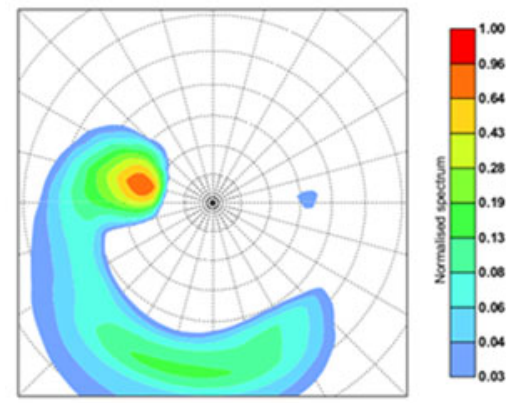

\section{Normalised 2D-spectrum on Oct. 18, 2015, 18 UTC at $72.5^{\circ} \mathrm{N}, 162.8^{\circ} \mathrm{W}$}

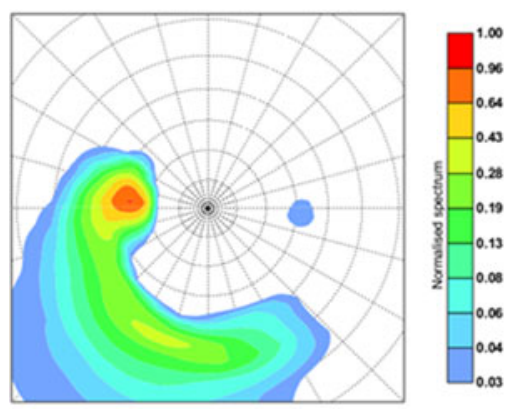

\section{Normalised 2D-spectrum on Oct. 18, 2015, 18 UTC at $72^{\circ} \mathrm{N}, 163.5^{\circ} \mathrm{W}$}

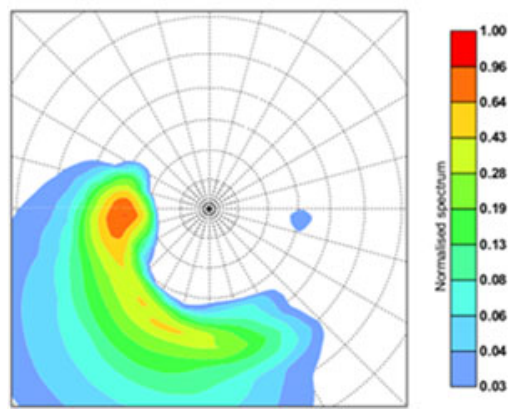

Fig. 8. Two-dimensional wave spectra from operational ECMWF analysis for October 18, 2015, at 18 UTC. The spectral energy (normalized by its maximum value) is provided as a function of frequency. The middle of each spectrum is zero frequency. It is surrounded by concentric circles in steps of $0.05 \mathrm{~Hz}$. Color scale on the right of each spectrum. Note that a wave system from the east yields a signal in the western part of the spectrum and vice versa. The geolocations of the spectra are provided in the spectrum headers. These geolocations are also marked in Fig. 6 by plus signs.

Of course, variations in wave height may be related to the field of swell waves. As follows from Section III-A, the swell waves were generated by winds well to the east of the Stripmap acquisition area. Along a few hundred kilometers to the east of it, the wave height exhibits some tendency to decrease at the coast of Northern Alaska and at the ice edge as evident from 

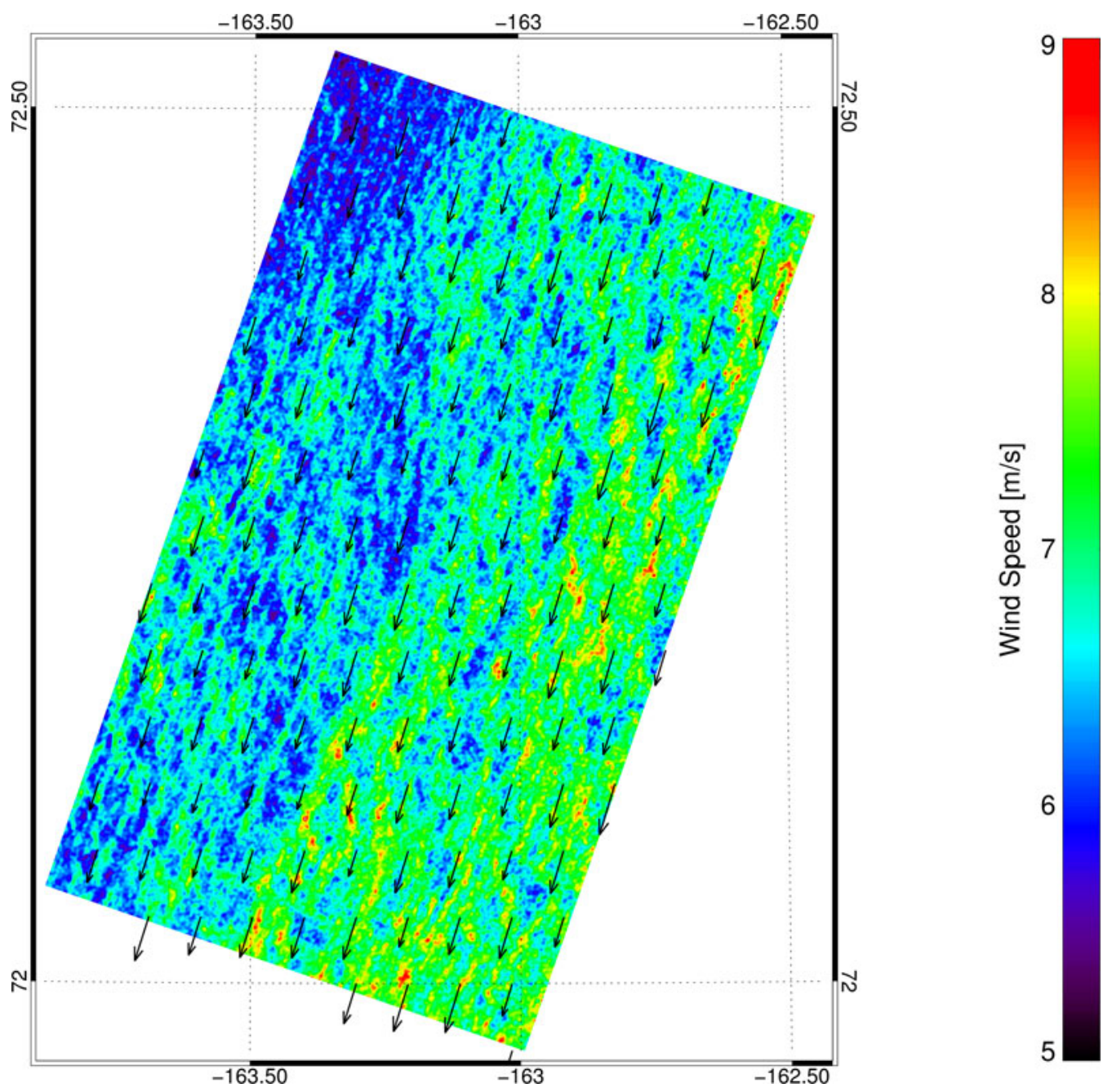

Fig. 9. Distribution of wind speeds is shown for satellite image 1. The data were determined at a much finer spatial resolution than for the wind plot in Fig. 6 (there, the same subscene size as for sea state analysis was used). For the purpose of demonstration, much smaller subscenes were used here. The plot clearly reveals wind streak patterns, which have close to northeasterly direction. Wind speeds are as well given by black arrows. Their length corresponds with the values of speed. The arrow direction is northeasterly, i.e., $45^{\circ}$. The latter is the a priori value of the wind direction, which was selected as input variable for the XMOD-2 algorithm.

the lower panel of Fig. 3. The latter is likely to be explained by reduced fetch arising from geometrical constraints due to surrounding land/ice. Similar observations are reported in [9]. As pointed out, other potential drivers of wave height decay at the ice edge are wave attenuation in partially ice-covered water and reduced wind speed over ice.

Another potential driver of wave height variability is the interaction with local winds. From the data plots in Fig. 6, it can be readily seen that the patterns of $H_{S}$ and $U_{10}$ data follow one another. The figure shows that $H_{S}$ increases by around $1 \mathrm{~m}$ from near the ice edge toward the bottom of the Stripmap scene. As noted in Section III-B, local winds are expected to be northeasterly. This points toward a fetch length on the order of 100-200 km between the ice edge and the bottom part of the Stripmap image (compared with the ice concentration map in Fig. 2). The observed increase of $H_{S}$ is well within the wave growth expected from fetch relations, with wind speeds being limited by values of 2 and $7.5 \mathrm{~m} \cdot \mathrm{s}^{-1}$, which is the range of the wind plot in Fig. 6, and the atmospheric stratification being unstable. Based on the fetch relations described in Section IV, empirically expected $H_{S}$ values are plotted as a function of the fetch for different wind speeds and unstable atmospheric condition in Fig. 7. As pointed out in Section III-B, the advection of relatively cold Arctic air over open water is a source for atmospheric instability.

\section{B. Nonlinear Imaging Effects}

Contrastingly, wind wave systems with wavelengths clearly shorter than those of the swell waves, described before, are not identifiable from visual inspection of satellite images and subscenes (compare Fig. 5). If present, their wavelength and direction may be in the nonlinear imaging regime of TS-X. The latter is both empirically known [18, appendix] and also expected from SAR imaging theory [6]. An upper limit of the short wavelengths possible here may be estimated as follows. Wave growth 
under unstable atmospheric stratification is assumed. For a fetch of $100 \mathrm{~km}$, larger-than-actual values of $10 \mathrm{~m} \cdot \mathrm{s}^{-1}$ are taken as wind speed. Using (2), (3), (5), and (6), this yields a value of wavelength of around $50 \mathrm{~m}$. If the wave propagation direction is close to the azimuth direction, this is still inside the nonlinear imaging regime of TS-X (compare [6, Fig. 11], curve for TS-X and $\Phi=0)$.

On the other hand, the imaging quality of the longer swell waves does not strongly suffer from SAR-specific nonlinear imaging effects. Arising from short and random water waves and turbulent water motion, nonlinear imaging effects produce image spectrum noise smeared out in the satellite cross-flight direction at small values of wavelengths. In [19], a quantity was introduced to estimate their potential to defocus or overlay short range traveling ocean waves, $R^{\text {in/out }}$. It is calculated as the ratio of the typical spectrum noise inside the domain with nonlinear imaging effects (cutoff) being of consequence to that outside. For long ocean waves being practically linearly imaged by SAR, $R^{\text {in/out }}$ approaches 1 , whereas values of 3-5 are indicative of strong impact. Here, intermediate values of $R^{\text {in/out }}$ were found. They are typically between 3 and 3.5 for images 1 and 2 and between 2 and 3 for image 3 . Typical image spectra like those in Fig. 5 do not exhibit very strong defocusing.

\section{Cross-Check With Operational ECMWF Data}

In Fig. 8, 2-D wave spectra for October 18, 2015, at 18 UTC, from operational ECMWF analysis are presented. The geolocations of all three wave spectra are also marked in Fig. 6. The ECMWF spectra indicate three wave systems with the dominant one being a swell from the east. In addition, there is a weak signal from another swell from the west. The dominant swell has a frequency of somewhat below $0.15 \mathrm{~Hz}$, which is around 100-m wavelength, and the weak swell of somewhat above 0.15 $\mathrm{Hz}$, which is $50-100 \mathrm{~m}$ wavelength. These wave systems are consistent with the wave spectra from TS-X shown in Fig. 5. They exhibit the highest spectral energy at wavelength between 50 and $100 \mathrm{~m}$ around the satellite cross-flight direction.

Moreover, the ECMWF wave spectra in Fig. 8 show a wind wave system. As typical for wind sea, the latter has considerable directional spread. The spectra indicate a relatively broad secondary maximum in the south-west-south direction. From the top to bottom spectrum of the figure, the corresponding wave frequencies are shifted toward lower values, i.e., the wavelengths increase. For the bottom spectrum, the wave frequencies still remain above $0.15 \mathrm{~Hz}$, i.e., the wavelengths are still smaller than $70 \mathrm{~m}$. As follows, the preferential direction of those waves is relatively close aligned with the satellite flight direction at the image acquisition. As already mentioned before, the latter is tilted clockwise by $19.5^{\circ}$ with respect to the north-to-south direction. Overall, this matches the scenario of short wind waves being in the nonlinear imaging regime of TS-X described in Section V-B.

Operational ECMWF analysis yields an $H_{S}$ value of $1.19 \mathrm{~m}$ associated with the top spectrum in Fig. 8. For the middle and bottom spectrum, $H_{S}$ is 1.35 and $1.48 \mathrm{~m}$, respectively. Thus, an increase of $H_{S}$ from the geolocation of the top spectrum toward that of the bottom spectrum is shown in qualitative agreement with TS-X data (compare Fig. 6).

\section{SUMmary AND CONCLUSION}

The basis for this investigation was a Stripmap scene from the TS-X satellite on October 18, 2015, at 18 UTC. The scene has a length of more than $100 \mathrm{~km}$ and the imaged area extends from the Arctic ice edge into the open water of Beaufort/Chukchi Sea. A field of swell waves was clearly revealed by TS-X.

The local meteorological situation is characterized by weak to moderate winds with considerable spatial variability. From the satellite scene, data on the significant wave height and wind speed were retrieved.

The wave height was detected to grow with increasing distance from the ice edge. Over the length of three single satellite images (single length is $30 \mathrm{~km}$ ), the significant wave height grew by around $1 \mathrm{~m}$. Consistent with empirical fetch relations, the estimated fetch of 100-200 km and rather moderate winds, under unstable atmospheric stratification, are quite sufficient for this.

As well, the possibility of local wind contributing to the observed wave height increase is supported by ECMWF data. This case study demonstrates that the wind wave interaction in marginal seas of the Arctic Ocean needs attention. This applies particularly in the context of the emergence of swell waves in those seas in recent times [24]. Both swell and local wind sea may contribute significantly to the overall sea state.

This paper provides an up-to-date insight in the possibility to monitor sea state in Arctic marginal seas using Stripmap scenes from the TS-X satellite. It is worthwhile pointing out that although short wind waves may not be (linearly) imaged by SAR, their contribution to the overall wave height is accounted for by the satellite retrieval algorithm used here. Data comparisons between SAR satellites and wave/ice models are of significant interest accordingly. An example satellite-to-model comparison in the Beaufort/Chukchi Sea was already shown in [9].

\section{REFERENCES}

[1] F. Ardhuin, "Estimates of ocean wave heights and attenuation in sea ice using the SAR wave mode on Sentinel-1A," Geophys. Res. Lett., vol. 42 pp. 2317-2325, 2015, DOI: 10.1002/2014GL062940.

[2] F. Ardhuin, P. Sutherland, M. Doble, and P. Wadhams, "Ocean waves across the Arctic: Attenuation due to dissipation dominates over scattering for periods longer than 19 s," Geophys. Res. Lett., vol. 43, pp. 5775-5783, 2016, DOI: 10.1002/2016GL068204.

[3] M. Bakhoday Paskyabi, S. Zieger, A. D. Jenkins, A. V. Babanin, and D. Chalikov, "Sea surface gravity wave-wind interaction in the marine atmospheric boundary layer," Energy Procedia, vol. 53, pp. 184-192, 2014. [Online]. Available: http://dx.doi.org/10.1016/j.egypro.2014.07.227

[4] M. Bruck and S. Lehner, "Sea state measurements using TerraSAR$\mathrm{X}$ data," in Proc. IEEE Int. Geosci. Remote Sens. Symp., 2012, pp. 7609-7612, [Online]. Available: http://dx.doi.org/10.1109/ IGARSS.2012.6351866

[5] C. O. Collins, III, W. E. Rogers, A. Marchenko, and A. V. Babanin, "In situ measurements of an energetic wave event in the Arctic marginal ice zone," Geophys. Res. Lett., vol. 42, pp. 1863-1870, 2015, DOI: 10.1002/2015GL063063.

[6] G. Diaz Mendez, S. Lehner, F. Ocampo-Torres, X.-M. Li, and S. Brusch, "Wind and wave observations off the south Pacific Coast of Mexico using TerraSAR-X imagery," Int. J. Remote Sens., vol. 31, pp. 4933-4955, 2010 , DOI: 10.1080/01431161.2010.485217. 
[7] T. Fritz, M. Eineder, J. Mittermayer, A. Roth, E. Boerner, H. Breit, and B. Braeutigam, "TerraSAR-X ground segment, basic product specification document," TX-GS-DD-3302, Issue 1.9., Oct. 2013. [Online]. Available: http://sss.terrasar-X.dlr.de/pdfs/TX-GS-DD-3302_1.9.pdf

[8] C. Gebhardt, J.-R. Bidlot, J. Gemmrich, A. Pleskachevsky, S. Lehner, and W. Rosenthal, "Wave observation in the marginal ice zone with the TerraSAR-X satellite," Ocean Dyn., vol. 66, pp. 839-852, 2016, DOI: 10.1007/s10236-016-0957-8.

[9] J. Gemmrich, A. Pleskachevsky, S. Lehner, and E. Rogers, "Surface waves in arctic seas, observed from TerraSAR-X." in Proc. IEEE Int. Geosci. Remote Sens. Symp., Milan, Italy, 2015, pp. 3615-3617, DOI: 10.1109/IGARSS.2015.7326604.

[10] K. Hasselmann et al., "Measurements of wind-wave growth and swell decay during the Joint North Sea Wave Project (JONSWAP)," Dtsch. Hydrogr. Z. A. ( $\left.8^{\circ}\right)$, vol. 12, pp. 1-95, 1973.

[11] K. Kahma and C. Calkoen, "Reconciling discrepancies in the observed growth of wind-generated waves," J. Phys. Oceanograph., vol. 22 , pp. 1389-1405, 1992.

[12] S. Lehner, A. Pleskachevsky, D. Velotto, and S. Jacobsen, "Meteo-marine parameters and their variability observed by high resolution satellite radar images," Oceanography, vol. 26, pp. 80-91, 2013. [Online]. Available: http://dx.doi.org/10.5670/oceanog.2013.36

[13] S. Lehner and B. Tings, "Maritime Products Using TerraSAR-X and Sentinel-1 Imagery," Int. Arch. Photogramm. Remote Sens. Spatial Inf. Sci., vol. XL-7/W3, pp. 967-973, 2015, DOI: 10.5194/isprsarchives-XL7-W3-967-2015.

[14] S. Lehner and J. Gemmrich, "Sea state events in the mariginal ice zone with TerraSAR-X satellite images," in Proc. IEEE Int. Geosci. Remote Sens. Symp., Beijing, China, 2016, pp. 2220-2222, DOI: 10.1109/IGARSS.2016.7729573.

[15] X.-M. Li and S. Lehner, "Algorithm for sea surface wind retrieval from TerraSAR-X and TanDEM-X data," IEEE Trans. Geosci. Remote Sens., vol. 52, no. 5, pp. 2928-2939, May 2014, DOI 10.1109/TGRS.2013.2267780.

[16] NOAA National Centers for Environmental Information, State of the Climate, "Synoptic Discussion for October 2015," Nov. 2015. [Online]. Available: http://www.ncdc.noaa.gov/sotc/synoptic/201510

[17] O. Persson, B. Blomquist, C. Fairall, and S. Pezoa, "Meteorological and ocean flux data recap," Presentation at the sea state workshop, Stennis, Hancock County, MS, USA, Feb. 19-21, 2016. (Presentation and data available upon request to O. Persson at ola.persson@ colorado.edu.)

[18] A. Pleskachevsky, S. Lehner, T. Heege, and C. Mott, "Synergy and fusion of optical and synthetic aperture radar satellite data for underwater topography estimation in coastal areas," Ocean Dyn., vol. 61, pp. 2099-2120, 2011, DOI: 10.1007/s10236-011-0460-1

[19] A. Pleskachevsky, W. Rosenthal, and S. Lehner, "Meteo-marine parameters for highly variable environment in coastal regions from satellite radar images," ISPRS J. Photogramm. Remote Sens., vol. 119, pp. 464-484, 2016. [Online]. Available: http://dx.doi.org/ 10.1016/j.isprsjprs.2016.02.001

[20] W. Rosenthal and J. Sündermann, Ed., Landolt-Börnstein-Group V Geophysics $3 C$ (Subvolume C), part 6.2. Berlin, Germany: Springer-Verlag, 1986.

[21] J. Schulz-Stellenfleth and S. Lehner, "Spaceborne synthetic aperture radar observations of ocean waves traveling into sea ice," J. Geophys. Res., vol. 107, pp. 20-1-20-19, 2002, DOI: 10.1029/2001JC000837.

[22] G. Spreen, L. Kaleschke, and G. Heygster, "Sea ice remote sensing using AMSR-E $89 \mathrm{GHz}$ channels," J. Geophys. Res., vol. 113, 2008, Art. no. C02S03, DOI: 10.1029/2005JC003384

[23] The SWAMP group, Ocean Wave Modeling. New York, NY, USA: Plenum, 1985.

[24] J. Thomson and W. E. Rogers, "Swell and sea in the emerging Arctic Ocean," Geophys. Res. Lett., vol. 41, pp. 3136-3140, 2014, DOI 10.1002/2014GL059983.

[25] J. Thomson, "ONR Sea State DRI Cruise Report, R/V Sikuliaq," Fall 2015. [Online]. Available: http://www.apl.washington.edu/project/ projects/arctic_sea_state/pdfs/cruise_report.pdf

[26] J. Thomson et al., "Emerging trends in the sea state of the Beaufor and Chukchi seas," Ocean Model., vol. 105, pp. 1-12, 2016. [Online]. Available: http://dx.doi.org/10.1016/j.ocemod.2016.02.009

[27] S. Zieger, A. V. Babanin, W. E. Rogers, and I. R. Young, "Observationbased source terms in the third-generation wave model WAVEWATCH," Ocean Model., vol. 96, pp. 2-25, 2015. [Online]. Available: http://dx.doi.org/10.1016/j.ocemod.2015.07.014

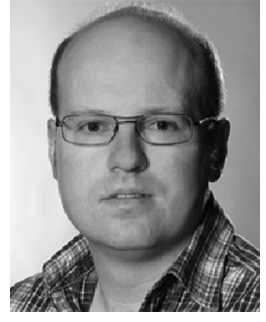

Claus Gebhardt studied physics at the Technical University of Berlin, Berlin, Germany, and the University of Bremen, Bremen, Germany. He received the Ph.D. degree in physics from the University of Bremen, in 2014. The focus of his Ph.D. studies was on chemical and physical processes in the Earth' atmosphere, on the basis of satellite-remote sensing data. He currently works in the field of ocean remote sensing with the Remote Sensing Technology Institute, German Aerospace Center (DLR), Bremen. His task is the extraction of multiple oceanic and atmospheric features from SAR satellite images, including meteo-marine parameters, bathymetry, and currents. This is followed by the validation of marine forecast models and studies in the field of sea state and climate research. He has been actively involved in remote sensing and research on ocean-atmosphere interactions since 2014 when he attended the "Earth Observation for Ocean-Atmosphere Interactions Science 2014" Conference, Frascati, Italy, October 28-31, 2014.

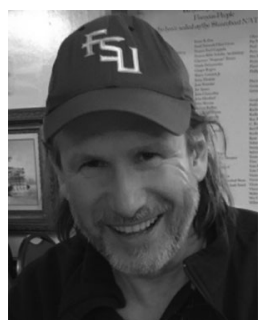

Jean-Raymond Bidlot received the Ph.D. degree in geophysical fluid dynamics from Florida State University, Tallahassee, FL, USA, working on aspects of western boundary currents such as the Gulf Stream.

$\mathrm{He}$ has been with the European Centre for Medium-Range Weather Forecasts (ECMWF), Reading, U.K., since 1995, developing the wave model and its coupling to other components of the forecasting system. This involves research and development in model physics and its associated numerical methods and includes technical and scientific integration with atmosphere and ocean model components of the system. He has also made ample use of wave observations for data assimilation and model validation. $\mathrm{He}$ is currently part of the coupled processes team of the research department, with a keen interest in studying the impact of the improved representation of interaction processes between the oceans, the waves, and the atmosphere on predictability capabilities of the ECMWF Earth System Model.

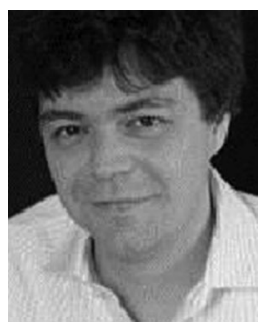

Sven Jacobsen received the Ph.D. degree in the field of space plasma physics at University of Cologne, Cologne, Germany, in 2011

$\mathrm{He}$ is the Head of the Maritime Safety and Security Lab, Bremen, Germany. As a geophysicist, he contributes expertise inter alia in nonlinear wave interactions and propagation. His scientific focus lies on wind and sea state retrieval on the basis of SAR images from different sensors and platforms.

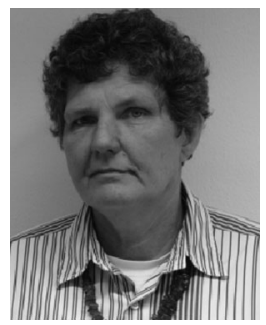

Susanne Lehner (M'99) studied mathematics and physics at the University of Hamburg, Hamburg, Germany. She received the M.Sc. degree in applied mathematics from Brunel University, Uxbridge, U.K., in 1979, and the Ph.D. degree in geophysics from the University of Hamburg, Hamburg, Germany, in 1984 .

During the Ph.D., she worked as a Research Scientist at the Max-Planck Institute for Meteorology, Hamburg. In 1996, she joined the German Aerospace Center DLR/DFD, Wessling, Germany, where she became the head of the team Radar Oceanography at the Institute for Remote Sensing Technology. She holds a faculty position at the Nova Southeastern University, Port Everglades, FL, USA. She became an Affiliated Faculty Member in 2013. Her SAR oceanography research focused on developing algorithms to extract information on wind fields, sea state, currents, and underwater topography from SAR images. In addition to global sea state measurements, her recent research interests have been in the high resolution coastal SAR oceanography, especially TerraSAR-X oceanography, meteo-marine observations, and maritime traffic surveillance in near real time. 


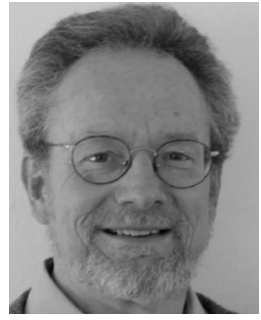

P. Ola G. Persson received the B.Sc. degree in meteorology and mathematics from Pennsylvania State University, State College, PA, USA, the M.Sc. degree in atmospheric sciences from the University of Washington, Seattle, WA, USA, and the Ph.D. degree in meteorology from Pennsylvania State University, in 1977, 1980 and 1991, respectively.

He is currently a Senior Research Scientist with the Cooperative Institute for Research in Environmental Sciences, University of Colorado, Boulder, CO, USA, working closely with the Physical Sciences Division of the NOAA/Earth Systems Research Laboratory. His research focuses on using observations and models for understanding physical processes impacting atmospheric boundary layers, cloud microphysics, and surface energy fluxes in polar regions; air-sea and air-sea-ice interactions; and mesoscale meteorology and dynamics, including airflow in complex terrain. He participated in collecting the Sea State dataset.

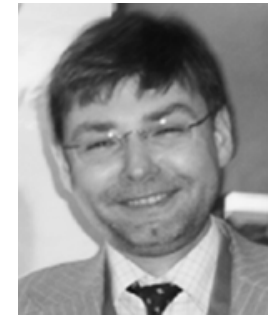

Andrey L. Pleskachevsky received the Diploma in hydropower engineering from the Technical University St. Petersburg, St. Petersburg, Russia, in 1994 in the field of hydrodynamic numerical modeling in coastal waters, and the Ph.D. degree with the thesis topic "coupled modelling of water waves, circulation and transport of radioactive contaminations in coastal waters" from the same university, with work performed at the GKSS-Research Center (HelmholtzZentrum Geesthacht), Geesthacht, Germany, in 1999.

From 1999 until 2009, he was a Research Scientist at the GKSS-Research Center at the Institute for Coastal Research, specialized in the coupling of spectral wave and circulation models as well as in the development of suspended matter transport models and in the implementation of satellite data into modeling. In 2009, he joined the Remote Sensing Technology Institute, German Aerospace Center (DLR), Wessling, Germany. Since the foundation of the DLR Maritime Safety and Security Lab, Bremen, Germany, in 2013 , he has been developing algorithms for the retrieval of sea state parameters from synthetic aperture radar data, sea state processors for near-real-time data services, and investigating ocean dynamics. 